\title{
EDITORIAL
}

\section{The butterfly rash of lupus: An example of aposematism?}

\author{
David S Pisetsky*
}

Even the most seasoned and savvy clinician views lupus warily, considering it one of the most bewildering diseases in all of medicine. This situation should not be a surprise since the manifestations of lupus are dizzying in their variety and exasperating in their subtlety. Furthermore, although lupus has been at the heart of immunology research for decades, investigators have yet to figure out its basis. Lupus represents a blatant violation of the most fundamental laws of the immune system. Nevertheless, the disturbances that dangerously turn self into non-self remain totally obscure.

The image of lupus adds to the confusion, although lupus actually has two competing images. These images, despite their differences, represent lupus's trademarks, its 'brand identity' so to speak. Lupus got its name from the wolf; its usual symbol, however, is the butterfly. I doubt that there are any two species as unlike one another in attitude, color, and emotional resonance as the wolf and the butterfly. Even if a misnomer, the word schizophrenic rightly describes this fierce battle of identity.

Branding a specific disease with the image of a creature comes with its hazards, and efforts to link a disease with a member of the animal kingdom are, in fact, unusual. Among the few associations that come to mind are icthyosis to describe skin that looks like fish scales; leonine facies, the lion-like visage of patients with lepromatous leprosy; and elephantiasis, the thickened skin and bulging extremities from filariasis.

In another realm, the term cancer stands as a general term for malignancy. Cancer is Latin for 'crab' and is one of the signs of the zodiac. No doubt, some old-time pathologist peering through a microscope thought that tumor cells looked like crazed crustaceans with pincers meant to harm. The term crab has another medical meaning since pubic lice are often called crabs. Pubic lice cause a nasty infestation, although the Phthirus pubis

*Correspondence: piset001@mc.duke.edu

Duke University Medical Center, 151G, Durham VA Medical Center, Durham, NC 27705, USA insects that besiege the groin really do look like crabs and most certainly bite.

The full name for lupus - systemic lupus erythematosus - is a mélange that roughly translates as a systemic disease in which a wolf turns red. The word lupus became part of the name since the lesions in the classic rash allegedly look like the bite or scratch of a wolf. Having never seen the aftermath of such an attack, I cannot verify this resemblance. Nevertheless, the association of a disease with a wolf is alarming. For much of history, wolves have been depicted in fables, myths, and even the Bible as menacing creatures that attack flocks and herds and even snatch little children. Sadly, the fear of wolves has led to extraordinary efforts at extermination, decimating the wolf population in many countries and creating havoc with the ecosystem. Notwithstanding the truth about these apex predators, the popular psyche has identified wolves as big and bad animals to be feared and despised.

As strange as it may be, the very same rash that led someone to think of Canis lupus led others to think of Danaus plexippus, as the monarch butterfly is officially known. I would argue that butterflies are among the sweetest and nicest members of the whole animal kingdom. If - in the minds of many - a wolf conjures up dark winter nights, howling cries, and assaults on sheep and little pigs, butterflies call forth warm sunny days on daisy-covered hills.

Images of butterflies abound throughout history, and depictions go back to Egyptian hieroglyphs. Butterflies appear on paintings, jewelry, and clothing. Whether embroidered with iridescent thread or painted with shiny lacquer, butterflies inspire thoughts of tranquility, peace, and love. For children, butterflies exist in the same sphere as bunnies, chicks, and unicorns. Currently, butterflies are popular for tattoos on young women, appearing on shoulders, backs, and bellies. I recently saw a young woman with a butterfly tattoo on her face. I wonder whether this choice was merely aesthetic or instead was an intentional allusion to a dreaded disease.

In modern health care, awareness and public education are top priorities to inform the public and alert policymakers to the personal, societal, and economic impact of 
disease. Lupus can be a very serious and disabling condition and, sadly, remains a killer. More awareness about lupus is desperately needed, as is more funding for research. Given these ever-pressing needs, it is reasonable to ask whether a butterfly is the right symbol to increase awareness. Is the butterfly linked too strongly with harmony and bliss to symbolize a disease that causes some of the most destructive forms of inflammation and tissue injury?

Recently, terminology has changed in medicine, especially for diseases that have received their designation from famous or, as it turns out, infamous physicians. Thus, Reiter's disease is now reactive arthritis and Wegener's granulomatosis is now granulomatosis with polyangiitis. These changes reflect the discovery of the roles of Reiter and Wegener during the Nazi era, although sometimes new names emerge from improved scientific understanding. The term rheumatoid spondylitis is, appropriately, gone.

If the name of a disease can change, how about its symbol? Would getting rid of the butterfly help the cause of lupus research and care?

I tend to be a commentator, not an advocate, and despite my interest in immunopathogenesis, I do not like to inflame or incite. I leave those jobs to others. But before passing this cause on to others, I decided to do some research on butterflies and make sure that dropping them as symbols would benefit rheumatology.

After consulting Wikipedia, the esteemed source of wisdom and knowledge even if some entries are suspect, I was reassured that the butterfly may be a reasonable symbol for lupus after all. Perusing what sounded like a very authoritative text, I discovered that butterflies exhibit three important traits: polymorphism, mimicry, and aposematism. Polymorphism signifies the variations in butterfly appearance that depend on locale, season, and infection. Polymorphism sounds right for lupus given its myriad presentations. Furthermore, polymorphism may be relevant in lupus because of the potential roles that viruses play in revving up the immune system to trigger disease and instigate flares.

A second feature of butterflies is mimicry since these insects can take on attributes of other species. Mimicry may be protective for the butterfly but can be problematic for the patient with lupus, which, as a mimic of diseases, can lead even the most astute diagnostician down the wrong diagnostic path.

The term aposematism was new to me. This word comes from the Greek apo- (meaning 'away from') and -semat ('sign') and indicates a change in appearance that can serve as a warning signal. Although aposematic signals can involve different senses like smell and hearing, coloration is the most striking example of this phenomenon. An ability to change color presumably evolved as a strategy to frighten predators away from a seeming source of danger.

As I was reading about aposematism, a gong went off in my head since, in many immune-mediated diseases, redness occurs prominently during their course. While I always assumed that redness - rubor, a cardinal sign of inflammation - resulted from hyperemia, another functional significance is possible. Perhaps redness during severe inflammation had its origin in aposematism, serving as a warning signal, not to predators but to family and friends, to stay away from a source of contagion. In immunology, we like to talk about danger signals but perhaps we should expand this idea to encompass warning signals. Autoimmune diseases can hijack the immune system to do very strange things. Coloration may be one.

Armed with knowledge from Wikipedia, I have concluded that the butterfly is an apt symbol for lupus. Indeed, in an unexpected way, it embodies some essential meanings about this disease. If a slogan is ever needed for lupus, however, I would move around the phylogenetic tree and go from lepidoptera to carnivora.

How about something strong and catchy like 'Treat lupus now, keep the wolf at bay'?

Published: 19 February 2013

doi:10.1186/ar4155

Cite this article as: Pisetsky DS: The butterfly rash of lupus: An example of aposematism? Arthritis Research \& Therapy 2013, 15:106. 